\title{
ÓNUS DE ALEGAR VERSUS ÓNUS DE CONCENTRAÇÃO: VARIAÇÕES NO DIREITO PROCESSUAL PORTUGUÊS
}

\author{
BURDEN TO PLEAD VERSUS BURDEN TO CONCENTRATE:
}

VARIATIONS IN PORTUGUESE PROCEDURAL LAW

Maria José Capelo ${ }^{1}$

\section{RESUMO}

O presente estudo debruça-se sobre o ónus de alegação, problematizando tanto o âmbito objetivo consoante a categoria do sujeito a quem é imputado (autor, réu ou executado) como as consequências da preclusão emergente da decisão transitada em julgado. Quanto ao autor, verificou-se que o entendimento dominante propugna pela liberdade de conformar o objeto da causa. Já, na perspetiva do réu, assinalou-se o ónus de concentração de toda a defesa na contestação, rejeitando-se, porém, a admissibilidade de um ónus de reconvir. Nos embargos de executado, à luz do atual direito português, questionou-se a razoabilidade da opção por um ónus de concentração de todos os meios atinentes à existência, exigibilidade e validade da obrigação sob pena de preclusão.

Palavras-chave: Ónus de alegação; Procedimento declarativo; Embargos de executado; Preclusão caso julgado.

\section{ABSTRACT}

Addressing the burden to plead, this study discusses both its full scope according to the type of person being charged (whether a plaintiff, a defendant or an enforcible debtor), and the consequences of the collateral estoppel arising from a final court decision. Regarding the plaintiff, it has been found that mainstream doctrine makes the case for a free determination of the object of the dispute. Concerning the defendant's standpoint, the burden to concentrate the whole defense in the statement of defense is highlighted, whereas the burden to counterclaim is rejected altogether. As for the judgment debtor's stay of execution, the A. wonders whether the burden to concentrate the whole defense pertaining to the existence, enforceability and validity of the obligation under the penalty of collateral estoppel, is a reasonable option in the framework of contemporary Portuguese law.

Keywords: Keywords: Burden to plead; Declaratory proceedings; Debtor's defense judgment debtor's stay of execution; Collateral estoppel. Res judicata.

\section{INTRODUÇÃO}

A necessidade de um processo eficiente, célere e pacificador de todos os contornos de uma relação jurídica controvertida condiciona a configuração dos ónus das partes ${ }^{2}$ e interfere

\footnotetext{
${ }^{1}$ Professora Associada da Faculdade de Direito da Universidade de Coimbra.

2 Cf., sobre conceito de ónus processual relacionando-o com o principio da autorresponsabilidade, sem deixar de evidenciar a sua "coloração publicística" (coloritura pubblicistica, por garantir a eficiência e a duração razoável do processo, CARRATTA, Antonio. II fondamento del principio
} 


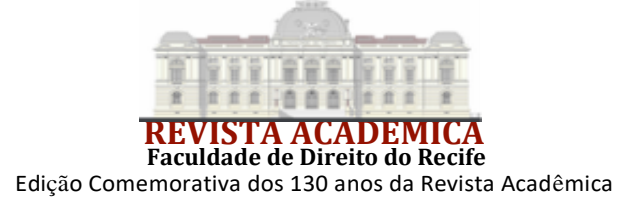

com as fronteiras do objeto sobre o qual se forma o caso julgado.

No que diz respeito ao ónus de alegação, a sua inobservância provoca tanto uma preclusão "interna" (dentro do processo) como externa, no sentido de se projetar noutros processos futuros sob a capa da autoridade de caso julgado.

$\mathrm{Na}$ ordem jurídica portuguesa, sem o suporte do artigo 508. ${ }^{\circ}$ do CPCbr (Código de Processo Civil do Brasil de 2015) ${ }^{3}$, o efeito preclusivo é "incorporado" na exceção de caso julgado ${ }^{4}$.

Assim explica Miguel Teixeira de Sousa a "transmutação" da preclusão em exceção de caso julgado:

“(...) primeiro, verifica-se a preclusão da prática do acto num processo pendente; depois, exactamente porque a prática do acto está precludida nesse processo, torna-se inadmissível a prática do acto num outro processo", pelo que (...) depois de haver no processo uma decisão transitada em julgado, a preclusão extraprocessual deixa de operar per se, passando a actuar através da excepção de caso julgado" 5 .

Também perspetivando a eficácia preclusiva como uma "consequência" do caso julgado, Sergio MenCHINI sustenta, de forma categórica, que o caso julgado impede a reapreciação de questões já submetidas à análise do primeiro juiz, mas também a invocação de questões que não foram feitas valer anteriormente, as quais, enquanto compreendidas no âmbito do objecto do procedimento anterior, podiam aí ter sido apreciadas ${ }^{6}$.

Tais questões constituirão a "res iudicanda" e sobre todas elas formar-se-á caso julgado, instituto processual através do qual se previnem decisões contraditórias ou repetidas sobre a relação jurídica litigiosa ${ }^{7}$.

Uma vez que o caso julgado se "serve" da figura da preclusão ${ }^{8}$ para estabilizar o

di preclusione nel processo civile, Il principio di preclusione nel processo penale. Torino: G. Giappichelli Editora, 2012, sobretudo p. 15-20. Vide, expondo, numa perspetiva histórica, a definição dos contornos dos conceitos de ónus e de deveres processuais e a sua assimilação pelo direito brasileiro, AzEvedo, Gustavo. Ônus e deveres processuais. Revista Acadêmica da Faculdade de Direito do Recife, v. 92, n. 2, p. 232-250, dez. 2020.

3 ANTONIO DO PASSO CABRAL encara a estabilidade do artigo 508. ${ }^{\circ}$ como uma "eficácia preclusiva" autónoma e independente da figura do caso julgado, embora complementar (cf., do Autor, Coisa julgada e preclusões dinâmicas: entre continuidade, mudança e transição de posições processuais estáveis. 3. ed. Editora JusPODIVM, 2018, sobretudo p. 326-329).

4 Cf., na doutrina clássica, ReIS, José Alberto dos. Código de Processo Civil Anotado. Coimbra Editora, 1984. p. 174-175. v. 5.; ANDRADE, Manuel A. Domingues de. Noções Elementares de Processo Civil. Coimbra Editora, 1979. p. 324.

5 Cf. Preclusão e Caso Julgado, in academia.edu/22453901/TEIXEIRA_DE_SOUSA_M._Preclusão_e_caso_julgad_02.2016, p.

22. Acesso em: setembro de 2021.

${ }^{6}$ Cf. MENCHINI, Sergio. Il giudicato civile. 2. ed. Torino: Utet, 2002. p. 53. O ilustre processualista italiano Chiovenda (Cf. Cosa giudicata e preclusione, Rivista Italiana per le Scienze Giuridiche, n. 11, p. 3, 1933,) sintetiza a relação entre o caso julgado e a preclusão com a seguinte formulação: "o caso julgado é um bem da vida reconhecido ou negado do juiz; a preclusão de questões é o expediente do qual o direito se serve para garantir ao vencedor o gozo do resultado do processo (...)".

7 ANTONIO DO PASSO CABRAL refere que o objetivo da eficácia preclusiva "é evitar a fraude de reprodução de demandas já debatidas anteriormente, com pequenas diferenças de conteúdo nas alegações" (cf. Coisa julgada e preclusões dinâmicas: entre continuidade, mudança e transição de posições processuais estáveis, cit., p. 117).

8 Esta preclusão atua independentemente da boa fé do sujeito onerado, por isso se afirma na doutrina alemã que estamos perante uma "preclusão objetiva" (cf. GOTTWALD, In: Münchener Kommentar zur Zivilprozessordnung mit Gerichtsverfassungsgesetz und Nebengesetzen [RAUSCHER, Thomas et al. (org.)], 6. Ed., Verlag C.H. Beck, 2020, § 322, anotação 143) 


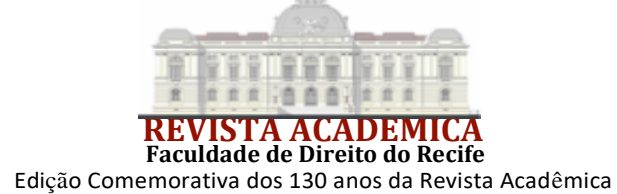

definido judicialmente, torna-se relevante apurar a maior ou menor extensão das preclusões que oneram cada uma das partes principais.

. Numa monografia sobre o objeto do processo e caso julgado, ANDRÉs DE LA OLIVA SANTOS $^{9}$ chamou a atenção para a incapacidade das teorias da substanciação e da individualização conferirem uma unidade conceitual ao objeto processual, denunciando o que se apelidou de "esquizofrenia" do objeto processual: o objeto que, por exemplo, tomamos em consideração para a determinação da congruência da sentença não é o mesmo a que recorremos para resolver questões relacionadas com o caso julgado. Em conformidade, defendeu que o objeto do processo precisa de ser encarado em dois planos: um interno, no sentido de se perspectivar o objeto de um processo nesse mesmo processo (objeto atual); e um plano externo que contende com a relação com outros processos e seus objetos (objeto virtual).

Esta ditinção entre um "objeto atual" e um "objeto virtual" tem como leit-motiv a Ley de Enjuiciamiento Civil de 2000, a qual prevê (como explicitaremos no ponto seguinte) um ónus de alegação (a cargo do autor) de todos os possíveis fundamentos fáticos e jurídicos (existentes ao tempo da propositura causa) do pedido formulado (afastando-se assim da teoria da substanciação).

Estará o sistema português imune a estes "objetos virtuais"?

Iremos, em seguida, debruçar-nos sobre o ónus de alegação a cargo das partes na ação declarativa (processo de conhecimento) e na execução (ou seja, nos embargos de executado) nas coordenadas emergentes do Código de Processo Civil de 2013.

\section{2 ÓNUS DE ALEGAÇÃO A CARGO DO AUTOR}

Nos termos do.$^{\circ} 1$ do $5 .^{\circ}$ do CPCPt (Código de Processo Civil Português), ao autor compete alegar os factos essenciais ${ }^{10}$ que constituem a causa de pedir ${ }^{11}$. Segundo MiguEL TEIXEIRA DE SOUSA, a orientação atualmente consagrada no direito português alude a uma conceção "deflacionista" da causa de pedir, "correspondente à chamada teoria da individualização aperfeiçoada, segundo a qual a causa de pedir é constituida apenas pelos

9 La Oliva Santos, Andrés De. Objeto del Processo y Cosa Juzgada en el Proceso Civil. Thomson-Civitas, 2005, sobretudo p.75-80.

${ }^{10}$ Se o facto é complementar ou concretizador, mas essencial à procedência da causa, o problema do ónus de alegação não se coloca de forma tão significativa, atendendo ao regime legal de consideração oficiosa [artigo $5 .^{\circ}, n^{\circ}$ 2, al. b), do CPCPt]. Além de que tais factos não têm autonomia jurídico-processual para fundamentarem uma nova ação. Vide, a este propósito, as nossas observações críticas sobre a adoção desta classificação legal de factos, «Os factos notórios e a prova dos danos não patrimoniais", Revista de Legislação e Jurisprudência, ano 143. [mar./abr. 2014], sobretudo p. 295-296. Na mesma linha crítica, MARIANA FRANÇA GOUVEIA afirma que esta categoria de factos complementares ou concretizadores, quando se utiliza no plano da alegação, tem um resultado desastroso (cf. O princípio dispositivo e a alegação de factos em processo civil: a incessante procura da flexibilidade processual, Revista da Ordem dos Advogados, ano 73, n. 2, p. 595-617, 2013, expressamente p. 19).

${ }^{11}$ Para efeitos de aferir a identidade de causa de pedir, numa sucessão de causas, interessa apurar se o acervo factual, alegado pelo Autor, diz respeito à mesma realidade fundamental, ainda que a sua específica alegação possa conter divergências ao nível dos factos não essenciais (cf. FREITAS, José Lebre de; AleXAndre, Isabel. Código de Processo Civil anotado. 3. ed. Coimbra: Almedina, p. 597-599. v. 2.). 


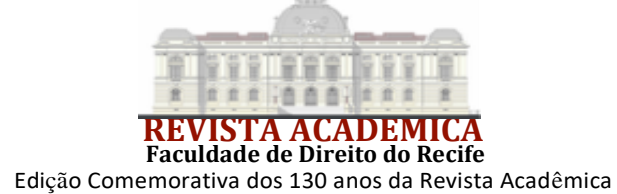

factos necessários à individualização do pedido do autor" ${ }^{12}$. Ou seja, a causa de pedir é mais restrita de que os factos necessários para a concludência ${ }^{13}$.

Seja qual for a extensão maior ou menor de factos a alegar ${ }^{14}$, é incontornável que no sistema português, o autor goza da liberdade de agir e de conformar o objecto da causa. Em caso de concurso de possíveis causas de pedir, o autor pode optar por as não concentrar num único processo.

Assim, se houver fundamento para intentar uma causa destinada a reivindicar um bem fundado em aquisição translativa derivada ou na posse conducente à usucapião ${ }^{15}$, goza o autor da prerrogativa de tratar, de forma separada, os objectos processuais. Em vez de intentar uma única acção de reivindicação fundada em duas causas de pedir, pode intentar primeiramente uma acção fundada num título de aquisição e, se esta improceder, é-lhe legitimo intentar num novo título jurídico, pois a autoridade de caso julgado formar-se-á sobre o pedido emergente da concreta causa de pedir ${ }^{16}$.

No Código de Processo Civil do Brasil, o artigo 508. ${ }^{\circ}$ estatuiu que, após o trânsito em julgado da decisão de mérito, «considerar-se-ão deduzidas e repelidas todas as alegações e as defesas que a parte poderia opor tanto ao acolhimento quanto à rejeição do pedido». Esta redação pode suscitar dúvidas sobre a extensão do ónus de alegação a cargo do autor, se recordarmos que no Anteprojeto, no artigo 489. ${ }^{\circ}$, se excluía deste efeito preclusivo a hipótese de ação fundada em causa de pedir diversa, ressalva que não ficou, porém, a constar da atual redação.

Todavia, num comentário à versão atual do artigo 508. ${ }^{\circ}$ do CPCbr, FREDIE DIDIER JR. explicita que é dominante o entendimento de que eficácia preclusiva «só atinge argumentos e provas que sirvam para embasar a causa petendi deduzida pelo autor» ${ }^{17}$.

Outra foi a linha seguida na Ley de Enjuiciamiento Civil de 2000.

No seu seu art. 400.1, determina-se: «Cuando lo que se pida en la demanda pueda fundarse en diferentes hechos o en distintos fundamentos o títulos jurídicos, habrán de

12 Cf. SousA, Miguel Teixeira de, «Algumas questões sobre o ónus de alegação e de impugnação em processo civil», Scientia Iuridica, n. ${ }^{\circ} 332$, p. 395-412, 2012. t. 62., especialmente p. 398.

${ }^{13}$ Perante esta mitigação do ónus de alegação, nos termos chancelados pelo al.b) do n. ${ }^{\circ} 2$ do artigo 5. ${ }^{\circ}$ do CPCPt, os factos complementares e concretizadores - que surjam durante o processo, sobretudo na fase instrutória - serão úteis para fundamentar e assegurar a concludência da pretensão da parte.

14 Vide, sobre a conceção dominante da causa de pedir através da teoria da substanciação no ordenamento processual brasileiro, antes da reforma de 2015, RODRIGUES, Marco António dos Santos. A modificação do pedido e da causa de pedir no processo civil. Rio de Janeiro: Mundo Jurídico, 2014. p. 44-51; e na vigência do novo Código de Processo Civil, referindo, em anotação ao artigo 319..$^{\circ}$, que o sistema brasileiro manteve sua opção pela teoria da substanciação, CoSTA, Susana Henriques da, In: Comentário ao Novo Código de processo Civil [CABRAL, Antonio do Passo; CRAMER, Ronaldo (coord)] p. 508.

${ }^{15}$ Vide, sobre as relações (de identidade, concurso ou cumulação) entre objetos processuais, SousA, Miguel Teixeira de, As Partes, o objecto e a prova na acção declarativa, Lisboa: Lex, 1995. p. 134-142.

${ }^{16}$ Cf. Artigos $581 .^{\circ}$ e $619 .^{\circ}$ do CPCPt.

17 Vide, com menção das correntes contrárias na interpretação da letra do artigo 508. ${ }^{\circ}$ do CPCbr, DIDIER JR., Fredie In: Comentário ao Novo Código de processo Civil [CABRAL, Antonio do Passo; CRAMER, Ronaldo (coord)], Rio de Janeiro: Forense, 2015. p. 783. No mesmo sentido, considerando que a eficácia preclusiva não veda uma ação fundada em nova causa de pedir, CABRAL, Antonio do Passo. Coisa julgada e preclusões dinâmicas: entre continuidade, mudança e transição de posições processuais estáveis, cit., p. 118. 


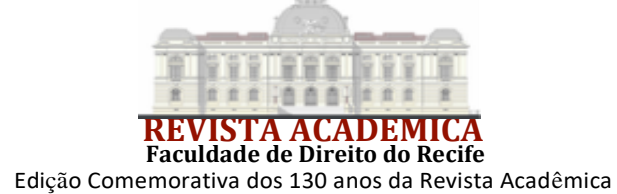

aducirse en ella cuantos resulten conocidos o puedan invocarse al tiempo de interponerla, sin que sea admisible reservar su alegación para un proceso ulterior «.

A propósito deste preceito, ISABEL TAPIA FERNÁNDEZ esclarece que:

“(...) o legislador outorga liberdade e autonomia ao sujeito jurídico para que configure a sua pretensão como melhor puder: mas adverte-o que não poderá voltar a pedir o mesmo baseado em diferente causa de pedir, porque se entende que esta (a causa de pedir) é idêntica à anterior ainda que se funde em factos ou fundamentos jurídicos diversos mas que eram conhecidos e podiam ter sido alegados naquele processo"18.

Com este expediente, tal como sublinha SONIA CALAZA LóPEZ, visa-se:

«a erradicação da massiva interposição de demandas que, formuladas de várias perspetivas, de diversos pontos de vista ou de múltiplos ângulos jurídicos, com o oculto - e, de certo modo, fraudulento - propósito de obter uma resposta judicial diferente à obtida em processo anterior, tratam em verdade de frustrar (burlar) o instituto do caso julgado» ${ }^{19}$.

Perante a preclusão que emerge da inobservância do ónus de alegar, a cargo do sujeito que assume o lado ativo, ANDRÉS DE LA OlIVA SANTOS/IGNACIO DIEZ -PICAZO GIMÉNEZ especificam que, para efeitos de caso julgado e litispendência, devemos servir-nos do conceito de objeto virtual (englobando todos os factos jurídicos de onde deriva o efeito jurídico pretendido, tenham, ou não, sido alegados e julgados). No entanto, dever-se-á lidar com o "objeto atual" para aferir, por exemplo, a competência do tribunal, a forma de processo, modificação da causa de pedir e o regime de recursos ${ }^{20}$.

Esta opção por um "ónus de concentração" não tem sido acolhido pacificamente. O pesado ónus que recai sobre o autor ${ }^{21}$ cerceia, de modo indireto, a sua liberdade de ação, e gera obstáculos, como denuncia SONIA CALAZA LÓPEZ, no modo de funcionamento de uma autoridade positiva do caso julgado (vinculação prejudicial da decisão num segundo processo). Esta formar-se-á sobre um objeto virtual, o qual pode não ter sido efetivamente apreciado $^{22}$. Ou seja, naqueles casos em que a decisão, revestida de autoridade, é pressuposto da segunda causa (um antecedente na apreciação da nova pretensão), a autoridade prejudicial $^{23}$ será mais ampla do que efetivamente foi apreciado (pois o caso julgado formar-

18 TAPIA FernÁndeZ, ISABEl. El objeto del processo. Alegaciones. Sentencia. Cosa Juzgada. Madrid: Editorial La Ley, 2000. p. 31.

${ }^{19}$ Vide, explicitando o propósito legal, SONIA CALAZA LÓPEZ, La cosa juzgada. Madrid: La Ley, 2009. p. 191.

${ }^{20}$ Cf. De La Oliva Santos, Andrés/DieZ -PiCAZo GiméneZ, Ignacio. Derecho Procesal Civil: el Processo de declaración. 3. ed. Editoral Universitaria Ramón Areces, 2004. p. 78.

${ }^{21}$ A propósito deste preceito, MONTERo ArocA, Juan et al (org.) (Derecho Jurisdiccional II (Proceso Civil). 21. ed. Valencia: Tirant Lo Blanch, 2013. p. 500) pronunciam-se, de forma crítica, exemplificando as consequências práticas do preceito com o seguinte exemplo: uma ação de nulidade do casamento pode fundamentar-se em diferentes factos, fundamentos ou títulos jurídicos nos termos do artigo $73 .^{\circ}$ do Código Civil Espanhol, mas no caso de o autor alegar só uma das causas (por exemplo falta de consentimento), se esta improceder, ficará precludida a alegação de novo fundamento (que já existia ao tempo da propositura da primeira ação). Vide, com muitas reticências, referindo que está em causa, na realidade, uma preclusão do direito de ação - CALAZA LÓPEZ, Sonia. La cosa juzgada, cit., p.185-199.

22 Cf. CAlAZA LóPEZ, Sonia. La cosa juzgada, cit., p. 198-199.

${ }^{23}$ A força de caso julgado de uma decisão é suscetível de revelar-se sob a forma de exceção dilatória, enquanto impedimento processual à apreciação de idêntico objeto, ou nas vestes de autoridade positiva, quando o que foi decidido, a título principal, é prejudicial numa segunda ação. LEBRE DE FREITAS, José/ISABEL ALEXANDRE são também esclarecedores na diferenciação entre exceção e autoridade positiva/prejudicial de caso julgado: «(...) a exceção de caso julgado não se confunde com a autoridade de caso julgado; pela exceção, visa-se o efeito negativo da inadmissibilidade da 


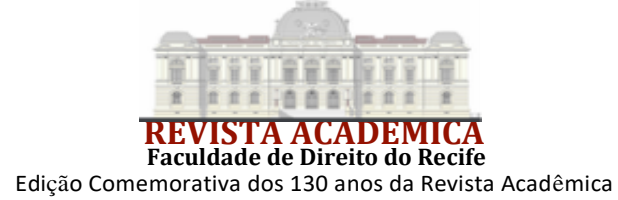

se-á sobre todas os fundamentos mesmo sobre aqueles que nunca foram trazidos aos autos). Ocorrerá uma espécie de "ficção" 24 de indiscutibilidade sobre o que não mereceu apreciação por parte do julgador, que dificilmente se compatibiliza com as garantias inerentes a um processo equitativo.

Outra questão diferente prende-se com a pertinência de um ónus de alegação de factos supervenientes constitutivos atinentesà relação jurídica controvertida.

\section{1 ÓNUS DE ALEGAÇÃO DE FACTOS CONSTITUTIVOS SUPERVENIENTES?}

Paralelamente à liberdade de agir e de conformar o objeto da causa, numa linha oposta poder-se-á indagar em que medida será razoável impor uma preclusão relativamente a factos constitutivos supervenientes que se revelem nos autos.

A passagem inexorável do tempo pode determinar alterações factuais, as quais têm influência sobre a existência ou conteúdo da situação litigiosa. Nesta medida, o artigo 663. ${ }^{\circ}$ do CPCPt impõe a sua atendibilidade e o artigo $588 .^{\circ}$ do CPCPt regula o procedimento, em contraditório, da assunção dos "novos" factos nos autos.

Como referem ANTUNES VARELA/M.BEZERRA/SAMPAIO NORA:

"o direito processual não manda julgar rigidamente a acção de acordo com a situação existente no momento da proposição da acção, declarando-se, pelo contrário aberto à consideração da evolução dinâmica da relação litigada, até ao momento derradeiro do encerramento da discussão da causa" 25 .

Por isso, a sentença deve reflectir a situação controvertida no momento do julgamento e não aquela que existia ao tempo da propositura da causa. $O$ expediente de assunção de factos novos com eficácia constitutiva, extintiva ou modificativa tem "(...) por finalidade viabilizar a solução definitiva do conflito e evitar o ajuizamento de novas demandas relativamente àquela mesma relação jurídica material"26.

A propósito da atendibilidade de fatos supervenientes no processo civil, LEONARDO CARNEIRO DA CUNHA sublinha que a sua admissibilidade é imposta pelo funcionamento de princípios essenciais do processo, tais como o princípio da boa fé, da cooperação e da duração razoável do processo. Enaltece a contraditoriedade, essencial à validade da assunção de factos supervenientes, mesmo quando estes causem alteração de causa de pedir

segunda ação, constituindo-se o caso julgado em obstáculo a nova decisão de mérito; a autoridade do caso julgado tem antes o efeito positivo de impor a primeira decisão, como pressuposto indiscutível de segunda decisão de mérito» - Cf. Código de Processo Civil Anotado, Volume 2. ${ }^{\circ}$, cit., p. 599. Cf., sobre o tema, CAPELO, Maria José, A Sentença entre a Autoridade e a Prova, Almedina, 2016, p. 51-56. Ver também, distinguindo exceção de caso julgado e autoridade positiva de caso julgado, MigUEL TeIXEIRA DE SOUSA. Estudos sobre o Novo Processo Civil. 2. ed. 1997. p. 572; e GERALDES, António Santos Abrantes; PIMENTA, Paulo; PIRES DE SOUSA, Luís Filipe. Código de Processo Civil Anotado I: Parte Geral e Processo de Declaração, 2. ed. 2021, p. 767-770.

24 A propósito do artigo 508..$^{\circ}$ do CPCbr, ANTÓNIO DO PASSO CABRAL refere que a lei brasileira estabeleceu uma ficção preclusiva da faculdade de alegar, que tem como resultado prático tornar irrelevantes os argumentos não aduzidos (cf. Coisa julgada e preclusões dinâmicas: entre continuidade, mudança e transição de posições processuais estáveis, cit., p. 118).

${ }^{25}$ Cf. VARela, João Antunes et al (org.). Manual de Processo Civil. 2. ed. Coimbra: Coimbra Editora, 1985. p. 681.

${ }^{26}$ Cf. CUNHA, Leonardo Carneiro da. A atendibilidade dos fatos supervenientes no processo civil: uma análise comparativa entre o sistema português e o brasileiro. Almedina, 2012. p. 88 (itálico do autor). 


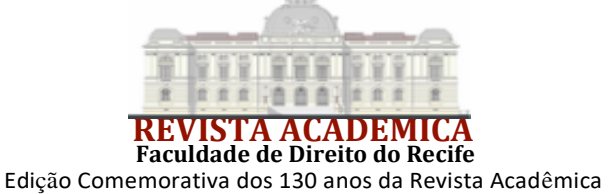

(embora pressupondo a não alteração da relação jurídica controversa) ${ }^{27}$.

E é sobretudo nestes casos em que os factos supervenientes acarretam a alteração de causa de pedir (não se circunscrevendo apenas aos factos que complementam a causa de pedir inicial $)^{28}$ que se questiona a legitimidade de imposição de um ónus de os alegar, com a ressalva de que a sua alegação não implique convolação para outra relação material controvertida.

Contudo, embora a leitura do artigo $588 .^{\circ}$ do CPCPt não vede esta faculdade de alterar a causa de pedir por via da apresentação de um articulado superveniente ${ }^{29}$, já dificilmente se encontra respaldo na letra do preceito para um ónus de alegação de factos constitutivos supervenientes.

No entanto, sob ponto de vista da eficiência processual, a importância de exaurir todos as vertentes factuais de uma determinada pretensão, sobretudo quando os factos "emergem" nos autos (nomeadamente por via da prova produzida), poderá justificar a defesa de um ónus de alegação a cargo do autor desses novos fundamentos. Um entendimento contrário prolongará a discussão em torno da mesma relação controvertida ${ }^{30}$, ou seja dá azo a que sejam intentadas novas ações fundadas em factos que podiam ter sido alegados porque conhecidos e provados, perturbando o primitivo réu com uma nova demanda e adiando a pacificação interpartes de uma situação litigiosa complexa.

A relevância de uma decisão temporalmente adequada terá justificado que o Código de Proceso Civil do Brasil não se tenha bastado com a assunção dos factos supervenientes mediante requerimento das partes, concedendo ao juiz a prerrogativa de tomar em consideração, ex oficcio, aqueles cuja existência está demonstrada nos autos (cf. Artigo $\left.493 .^{\circ}\right)^{31}$.

No actual modelo cooperativo, com grande flexibilidade processual e liberdade de actuação, as exigências decorrentes da boa-fé processual são incontornáveis. O processo civil já não é um campo de "batalhas privadas", mas move interesses públicos que impõem uma efectiva, rápida e justa resolução do litígio. A boa-fé condiciona, por conseguinte, a livre actuação das partes aos fins do processo, impedindo comportamentos desleais e contraditórios $^{32}$, recaindo, em, conformidade, sobre as partes, os ónus de carrearem para o processo todos os factos relevantes para a apreciação da situação litigiosa.

Como acentua ANTÓNIO DO PASSO CABRAL, se o acto processual é manifestação de vontade, também deve ser encarado como um acto de responsabilidade "e o legislador deve

${ }^{27}$ Altera-se a causa de pedir remota, não modificando a causa de pedir próxima (cf. CUNHA, Leonardo Carneiro da, op. cit., sobretudo pp 100 e 101.

28 Vide, admitindo a alteração ou ampliação da causa de pedir fora do circunstancialismo dos artigos $264 .^{\circ}$ e $265^{\circ}$, Freitas, José Lebre de; AleXANDRE, Isabel. Código de Processo Civil Anotado. v. 2., cit., p. 615-616.

${ }^{29} \mathrm{Sem}$ as restrições dos artigos $264 .^{\circ}$ e $265^{\circ}$ do CPCPt.

${ }^{30}$ Num entendimento diferente, MIGUEL TEIXEIRA DE SOUSA sustentou que o "autor não tem o ónus de invocar um facto constitutivo do direito que alega em juízo, embora tenha o ónus de alegar a verificação superveniente de um facto alegado", concluindo que, "no âmbito da superveniência, vale, para o autor, um ónus de concentração mitigado e, para o réu, um ónus irrestrito (cf. Preclusão e Caso julgado, cit., p. 3).

31 cf. DidiER JR, Fredie; Oliveira, Rafael Alexandria de; Braga, Paula Sarno. Comentários ao Novo Código de Processo Civil, cit., p. 737.

${ }^{32}$ Cf., sobre o princípio da boa-fé processual no sistema brasileiro, DIDIER JR, FREDIE. Curso de Direito Processual Civil, v. 1, 17. ed, p. 104. 


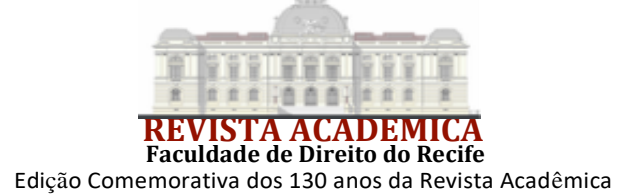

restringir as suas possibilidades de contradição com outras condutas" 33 . Nesta perspetiva, uma vez que o direito processual proíbe (ou deve proibir) um comportamento incompatível com condutas processuais anteriormente tomadas, se o ato incompatível tiver sido praticado fora do processo ou em processo diverso, "a contradição entre os comportamentos poderá ser invalidada ou inadmitida por aplicação do nemo potest venire contra factum proprium" 34 .

Nestas diretrizes de protecção da confiança e de respeito pela boa fé, será razoável sustentar que, naqueles casos em que o autor teve conhecimento de um facto no decurso do processo e não o aproveitou, e, posteriormente, perante a improcedência, o invoca como fundamento principal de uma "segunda acção" para obter o mesmo efeito jurídico, evidencia uma conduta "contraditória", suscetível de configurar, por conseguinte, em determinados pressupostos, uma manifestação de abuso do processo ${ }^{35}$.

Outra questão - que aqui não desenvolveremos - diz respeito à relação entre a responsabilidade civil processual e as situações de abuso do processo. Nos termos do artigo 542..$^{\circ}$ do CPCPt, a litigância de má-fé abarca comportamentos processuais que se desviem de um padrão de conduta honesto, correto e leal (boa-fé objetiva), desde que tais comportamentos sejam acompanhados da má-fé subjectiva (dolo ou negligência). O n. ${ }^{\circ} 2$ do artigo 542. ${ }^{\circ}$ do CPC exige, por conseguinte, o elemento subjectivo (má-fé subjectiva) como pressuposto integrante da responsabilidade processual. Todavia, o âmbito das situações que configuram um abuso do processo (e dos seus instrumentos) pode não coincidir com o da figura da litigância de má-fée ${ }^{36}$. Aonde houver coincidência, prevalecerá a litigância de máfé como instituto especial. Fora desse campo, o abuso do direito de acção "faz sempre nascer a obrigação de cessar o abuso" 37 , o que processualmente - perante a máxima Nemo potest venire contra factum proprium - traduzir-se-á numa decisão de extinção da instância sem conhecimento do mérito.

\section{3 ÓNUS DE CONCENTRAÇÃO DE TODA A DEFESA NA CONTESTAÇÃO}

Por efeito do ónus de concentração de todos os meios de defesa na contestação ${ }^{38}$, e sob pena de preclusão (artigo 573. ${ }^{\circ}$ do CPCPt), «obriga-se o réu, em homenagem ao princípio basilar da boa-fé processual (do "jogo franco e leal"), a apresentar na contestação todos os meios de defesa de que disponha nesse momento, sem distinção da sua menor ou maior

33 Cf. Cabral, António do Passo. Nulidades no Processo Moderno: Contraditório, Protecção da Confiança e Validade Prima Facie dos Atos Processuais. Rio de Janeiro:Editora Forense. 2. ed. 2010. p. 303.

34 CABral, António do Passo. Nulidades no Processo Moderno: Contraditório, Protecção da Confiança e Validade Prima Facie dos Atos Processuais, cit., p. 308. Refere, entre outros exemplo, o caso em que o Supremo Tribunal afirmou que uma parte que se recusa a fazer exame de DNA, não pode, posteriormente, após o trânsito em julgado, propor acção de anulação do registo sob o argumento de que agora pretende realizar o exame (loc.cit).

35 Após ter sublinhado a relevância da boa-fé no processo civil, MENEZES CORDEIRO afirmou que esta se repercute nomeadamente na proibição de venire contra factum proprium - Cf. CORDEIRO, António Menezes. Litigância de Má-fé, Abuso do direito de acção e culpa "in agendo". 3. ed. Almedina, 2016, p. 141-142; no mesmo sentido, Pedro de Albuquerque. Responsabilidade processual por litigância de má fé, abuso de direito e responsabilidade civil em virtude de actos praticados no processo. Almedina, 2006. p. 76-77.

36 Cf. CordeIro, António Menezes, op. cit., p. 146-147.

37 Cf ; CORDEIRO, António Menezes, op. cit., p. 147.

38 Ressalvados os meios de defesa supervenientes (cf. n. 2 do artigo 573. ${ }^{\circ}$ do CPCPt). 


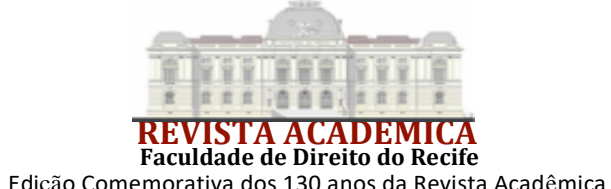

Edição Comemorativa dos 130 anos da Revista Acadêmica

eficiência» ${ }^{39}$.

Esta preclusão repercute-se, nestes termos, no alcance objetivo do caso julgado, que se pode tornar mais amplo do que efetivamente foi decidido (na perspetiva do sujeito que assumiu a posição de réu $)^{40}$.

A propósito da preclusão de todos os possíveis meios de defesa, MANUEL DE ANDRADE escreveu: «se a sentença reconheceu no todo ou em parte o direito do autor, ficam precludidos todos os meios de defesa do réu, mesmos os que ele não chegou a deduzir e até os que ele poderia ter deduzido com base num direito seu (por ex: ser ele, Réu, o proprietário do prédio reivindicado $)^{41}$.

Pela força de caso julgado, tornam-se irrelevantes (e inoperantes) as questões ligadas ao mérito que poderiam ter sido debatidas no processo (mas não o foram).

Isto é, não podem servir de base, a novas ações, factos que, num processo antecedente, poderiam - e deveriam, no caso de existirem - ter sido alegados, pelo réu, para impedir o reconhecimento do direito do autor, consubstanciando, por conseguinte, exceções perentórias $^{42}$ no sentido do n. ${ }^{\circ} 3$ do artigo $576 .^{\circ}$ do CPCPt. Ou seja a falta da alegação preclude, numa futura causa, a dedução de todo o circunstancialismo fático incompatível ${ }^{43}$ com o resultado atingido na ação pretérita (favorável ao autor).

Em suma, numa nova causa intentada pelo primitivo réu (nas vestes de autor) com fundamento em factualidade cuja alegação está precludida, não pode o tribunal apoiar-se nessa alegação para dela retirar um efeito que contrarie decisão transitada ${ }^{44}$. Ocorrerá, neste circunstancialismo, impedimento processual a uma pronúncia de mérito.

Saliente-se que a "irrelevância" dos fundamentos precludidos não significa que o tribunal os ignore. Ao invés, deve pronunciar-se no sentido de estar vedado ao tribunal o seu julgamento para deles extrair efeitos extintivos, modificativos ou impeditivos ${ }^{45}$. Este

39 Cf. Varela, João Antunes et al (org.). Manual de Processo Civil, cit., p. 311.

40 Vide, distinguindo o âmbito da preclusão factual consoante se trate do autor ou do réu, ALMEIDA, Francisco Manuel Lucas Ferreira de. Direito Processual Civil. 2. ed, Almedina, 2019, v. 2, expressamente p. 728-729.

${ }^{41}$ ANDRADE, Manuel A. Domingues de. Noções Elementares de Processo Civil. Coimbra Editora, 1979. p. 324

${ }^{42}$ Nesta linha, também Mendes, João de Castro (Limites objetivos do Caso Julgado, Lisboa: Ática, p. 176-177) assinala: “(...) ao passo que o autor não tem o ónus de fundamentação exaustiva da sua demanda, e por isso em caso de rejeição esta, pode repeti-la com outra causa de pedir, o réu tem o ónus da fundamentação exaustiva da sua defesa: em caso de rejeição desta, preclude-se a possibilidade de invocar outros meios de defesa (...)".

$43 \mathrm{Na}$ compreensão do caso julgado não nos podemos esquecer, como bem assinalou Manuel A. Domingues de ANDRADE (Noções Elementares de Processo Civil, cit., p. 317-318) que "o caso julgado só se destina a evitar uma contradição prática de decisões, e não já a sua colisão teórica ou lógica. Pouco lhe interessa que possam ser resolvidas diversamente pelo tribunal questões cujos elementos de direito, ou mesmo de facto, sejam idênticos, pois "o caso julgado, por sua parte, só pretende obstar a decisões concretamente incompatíveis (...)".

${ }^{44}$ RUI PINTO escreve que «(...) em caso de caso julgado positivo, para o réu vencido a condenação no pedido determina a preclusão de alegabilidade futura tanto dos fundamentos de defesa deduzidos, como dos fundamentos de defesa que poderia ter deduzido» anotando que «(...) tampouco o pode fazer em (i) ação autónoma ou em (ii) reconvenção, porque lhe vai ser oposta a autoridade de caso julgado, decorrente da vinculação positiva externa ao caso julgado assente no artigo $619 .^{\circ}$, em sede de objetos em relação de prejudicialidade». (Cf. Exceção e autoridade de caso julgado - algumas notas provisórias, Julgar Online, p. 42, nov. 2018.).

45 Em conformidade, intentada uma causa fundada num facto precludido, o tribunal deve absolver o réu da instância [cf. art. 577..$^{\circ}$ al. i), 576. ${ }^{\circ}$, n. $^{\circ}$ 2, ambos do CPC] com fundamento na verificação 


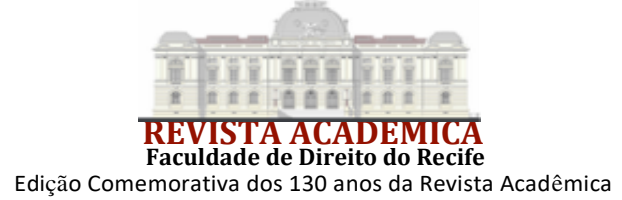

"obstáculo" ao conhecimento do fundo da causa operará através do recurso à exceção de caso julgado, prevenindo-se, por esta via, a emergência de uma situação contraditória com aquela que ficou definida na decisão transitada em julgado ${ }^{46}$.

\section{4 ÓNUS DE RECONVIR}

A formulação de um pedido reconvencional é, em regra, uma mera faculdade, não um ónus. Será um ónus naqueles casos em que a lei excecionalmente o preveja ${ }^{47}$.

Na doutrina (e jurisprudência portuguesa) têm surgido posições no sentido de sufragar um ónus de reconvir, com inspiração na figura norte americana da "compulsory

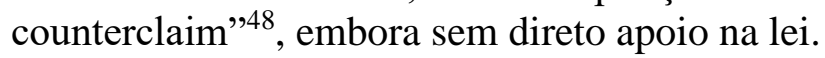

Num Acórdão do Supremo Tribunal de Justiça de $2012^{49}$, entendeu-se que da procedência de uma primeira causa de reivindicação resultava a impossibilidade de discussão acerca da propriedade do mesmo imóvel, em nova causa, com fundamento em diferente título (movida pelo primitivo réu). Tal impossibilidade resultava da existência de um ónus de

da exceção de caso julgado (neste sentido, Miguel Teixeira de Sousa, Preclusão e Caso Julgado, cit., p. 16).

46 Cf., sobre a eficácia de caso julgado como excludente de toda a situação contraditória ou incompatível com aquela que ficou definida na decisão transitada em julgado, SousA, Miguel Teixeira de. Estudos sobre o novo processo civil. 2. ed. Lex, 1997. p. 579; e do mesmo Autor, explicitando o âmbito do "contrário contraditório", «Preclusão e "contrário contraditório», cit., sobretudo p. 24-26. Na influente doutrina alemã defende-se a identidade do objeto processual não apenas quando se repete o pedido mas também quando se ambiciona o "contrário contraditório" (kontradiktorische Gegenteil) do que já foi declarado judicialmente. Cf. MUSIELAK; VOIT; ZPO. Zivilprozessordnung. 17. ed, Verlag Franz Vahlen; München, 2020, § 322, anotações n. ${ }^{\circ} 21$ a 25; e no mesmo sentido GOTTWALD, In: Münchener Kommentar zur Zivilprozessordnung mit Gerichtsverfassungsgesetz und Nebengesetzen, cit., $\S 322$, sobretudo anotações $n .^{\circ} 43$ a 45 .

${ }^{47}$ A título excecional, o nosso legislador tipifica, de forma expressa, ónus de reconvir, condicionando a liberdade de agir do sujeito que assuma o estatuto de réu. Um dos casos paradigmáticos de ónus de reconvir esteve consagrado no . $^{\circ} 2$ do artigo $1792 .^{\circ}$ do CC (na versão anterior à Lei n. $^{\circ}$ $61 / 2008$, de 31 de outubro) relativamente à dedução da pretensão de indemnização por danos não patrimoniais no contexto de uma ação de divórcio. Também o artigo $1551 .^{\circ}$, n. $^{\circ} 1$, do Código Civil, consagra um ónus de deduzir a pretensão de aquisição do prédio encravado a deduzir pelo proprietário do prédio serviente demandado pelo proprietário do prédio dominante para constituição coerciva de uma servisão de passagem sobre aquele.

${ }^{48}$ Cf., propugnando em alguns casos a figura do ónus de reconvir como expediente de prevenção de casos julgados incompatíveis e contraditórios, MESQUITA, Miguel, Reconvenção e Excepção no Processo Civil, Almedina, 2009, p. 439 et seq.; SousA, Miguel Teixeira de. Preclusão e “contrário contraditório. Cadernos de Direito Privado. n. 41, cit., p. 24-28; e FrEITAS, JOSÉ LEBRE DE. Um polvo chamado autoridade de caso julgado. Revista da Ordem dos Advogados, Lisboa, n. 3-4, 2019, p. 691-722, expressamente p. 709-710. Figura que já encantou a nossa jurisprudência. Assim, por exemplo, para além do Acórdão do STJ, de 10.10.2012,acima referenciado; Acórdão do Supremo de 5/9/2017, Processo 6509/16.7T8PRT.P1.S1; Acórdão do STJ, Processo 3074/16-9T8STR.S1, de 30/11/2017 (disponíveis em www.dgsi.pt. Acesso em setembro de 2021).

49 Acórdão do STJ, de 10.10.2012, Proc. nº 1999/11.7TBGMR.G1.S1. Numa anotação a este Aresto, MIGUEL TEIXEIRA DE SOUSA preconiza uma improcedência do pedido por preclusão do ónus de deduzir (reconvir) a acessão [ « (...) o reconhecimento da propriedade obtida na primeira ação não pode ser contrariado por factos que podiam ter sido alegados na correspondente acção e, que por esse motivo, se encontram precludidos»] - «Preclusão e "contrário contraditório», Cadernos de Direito Privado, n. 41, cit., p. 24 a 28. 


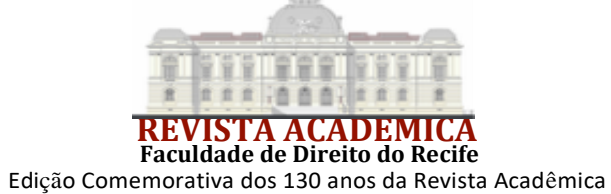

reconvir a aquisição da propriedade (por via da acessão imobiliária - figura prevista no artigo $1340{ }^{\circ}$ do Código Civil portuguêe ${ }^{50}$ ) na primitiva ação, pelo que ficara precludido a alegação deste direito potestativo a adquirir. Para o Juiz Conselheiro ABRANTES GERALDES a impossibilidade de discussão acerca da propriedade de um imóvel, em nova causa, com fundamento em diferente título, resultava da existência de um ónus de reconvir a cargo do primitivo réu ( isto é, na ação pretérita, que correu entre as mesmas partes, ficou "esgotada" a discussão sobre os possíveis títulos aquisitivos por parte do réu, incompativeis com a pretensão do autor) ${ }^{51}$.

Num estudo profundo sobre a reconvenção e o ónus de reconvir, o jurista alemão WOLFANG HAU refere que é muito questionável que se "importe" a figura da "compulsory counterclaim" para outros ordenamentos, pois este instituto é o complemento lógico da forma como é aplicada a doutrina do caso julgado na ordem judicial norte-americana. Este sistema processual incentiva a "concentração" - um verdadeiro ónus de concentração como o apelida Wolfang $\mathrm{HAU}^{52}$ - de pretensões/defesas numa única causa. O que terá determinado inclusive que se regulamentasse, expressamente ${ }^{53}$, a figura da reconvenção necessária ${ }^{54}$, não remetendo a sua "criação" para o âmbito de precedente judicial.

Ou seja, a res judicata ${ }^{55}$ norte americana "está muito longe" do caso julgado restrito ao pedido (fundado numa específica causa de pedir) ${ }^{56}$ dos regimes europeus, pois pressupõe um verdadeiro ónus de concentração não apenas na perspetiva do réu como daquela preconizada pelo autor. Este sistema preclusivo alicerça-se na figura da claim preclusion e na da issue preclusion, significando a primeira a proibição de renovação do litígio ${ }^{57}$ e a

${ }^{50}$ Nos termos do artigo $1340 .^{\circ}$, n. $^{\circ}$ 1, do Código Civil Português: "Se alguém, de boa fé, construir obra em terreno alheio, ou nele fizer sementeira ou plantação, e o valor que as obras, sementeiras ou plantações tiverem trazido à totalidade do prédio for maior do que o valor que este tinha antes, $o$ autor da incorporação adquire a propriedade dele, pagando o valor que o prédio tinha antes das obras, sementeiras ou plantações".

${ }^{51}$ Cf. Acórdão referenciado supra do STJ, de 10.10.2012, Proc. nº 1999/11.7TBGMR.G1.S1.

${ }^{52}$ Cf. HAU, Wolfang, Widerklageprivileg und Widerklagelast, Zeitschrift für Zibilprozess, 1, 2004, p. 31-58, expressamente p. 58 .

${ }^{53}$ Cf. 13. ${ }^{\mathrm{a}}$ Regra da Federal Rules of Civil Procedure.

54 Vide, explanando o âmbito objetivo da "res judicata" norte americana, relacionando-o com um ónus de alegação a cargo do autor e do réu, NIEHOFF, Gerrit Cornelius, Verfahrenskonzentration durch compulsory counterclaim in den US-amerikanischen Zivilprozessordnung, Mohr Siebeck, 2014, sobretudo p. 74-99.

${ }^{55} \mathrm{Cf}$, assinalando alguma "flutuação" no uso do termo res judicata, umas vezes utilizado no sentido amplo (englobando tanto a claim preclusion como a issue preclusion), noutra vezes reportandose a res judicata, tão só, à claim preclusion, e a figura da issue preclusion ao collateral estoppel, NIEHOFF, Gerrit Cornelius, ob. cit., p. 9.

56 Sublinhando, de forma clara, as diferenças da res judicata norte americana e os efeitos de uma decisão de mérito em países de experiência europeia-continental, VOLPINO, Diego, L'oggetto del giudicato nell'esperienza americana, Cedam, 2007, sobretudo p. 287 et seq. O instituto da res judicata norte-americana «(...) por meio de desenvolvimento de regras contra a divisão da causa de pedir (...) e pressões sistémicas para que o réu alegue obrigatoriamente certas questões no mesmo processo (...) encontrou terreno fértil para se expandir e cobrir não apenas a específica demanda proposta, mas o conflito in natura (CABRAL, António do Passo, Coisa julgada e preclusões dinâmicas: entre continuidade, mudança e transição de posições processuais estáveis, cit., p. 214)

57 A propósito da claim preclusion, é interessante anotar a extensão da preclusão tal como decorre do $\S 24$ Restatement (second) of Judgments: « (...) the claim extinguished includes all rights of the plaintiff to remedies against the defendant with respect to all or any part of the transaction, or series of connected transactions, out of which the action arose». Cf., sublinhando as "generosas" regras norte-americanas, que potenciam a resolução de maior número de questões (e sujeitos) 


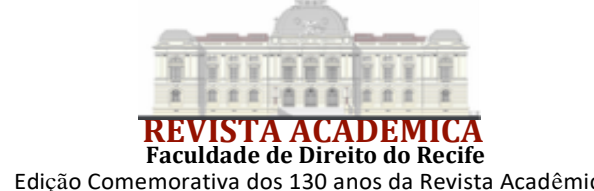

segunda a proibição de reexame das questões em diferente causa ${ }^{58}$.

Fora deste contexto jurídico, qualquer política legislativa no sentido de, no futuro, configurar hipóteses de reconvenção necessária (e não facultativa) enfrentará o risco, de privar o réu "da faculdade de escolher o momento e o local (o tribunal) para realizar a sua pretensão, o que fragiliza o princípio do acesso ao Direito e aos Tribunais, maxime, no que tange à igualdade no acesso à Justiça e aos Tribunais" ${ }^{59}$.

Os nossos Tribunais devem julgar de acordo com o direito constituído, resistindo à "importação" tentadora, mas superficial, de institutos típicos de ordenamentos alheios à tradição de civil law, tal como a figura da reconvenção obrigatória, cuja compreensão é indissociável das especificidades da res judicata norte americana ${ }^{60}$.

A consagração legal de um ónus de reconvir só é tolerável a título muito excecional, pois fere os princípios da disponibilidade da tutela jurisdicional ("liberdade de decisão sobre a instauração do processo" ${ }^{61}$ ), do contraditório e da igualdade de acesso aos Tribunais.

Assinale-se a nítida "distância conceitual” que perpassa entre a reconvenção e a alegação de causas impeditivas, extintivas ou modificativas do direito do autor (exceções perentórias): o fim pretendido não é a absolvição do pedido formulado pelo autor, mas antes se almeja a satisfação de um direito próprio, sendo que a apreciação judicial (deste) está dependente da procedência do pedido principal.

Visando-se, com a apresentação de uma reconvenção, a tutela um direito próprio, é lógico que o sujeito que assume o estatuto de réu não possa ser "pressionado", em regra, a exercê-lo em juízo. A faculdade de deduzir a reconvenção é um privilégio concedido ao réu em nome do princípio dispositivo ${ }^{62}$.

\section{5 ÓNUS DE ALEGAÇÃO NOS EMBARGOS DO EXECUTADO}

$\mathrm{Na}$ doutrina brasileira problematiza-se o âmbito da eficácia preclusiva do caso julgado nos embargos à execução, invocando-se a diretriz constante do artigo 508. do CPCbr. Eis a questão colocada por FREDIE DIDIER JR.:

“(...) julgados improcedentes embargos à execução opostos com base em fundamento (considerado como sua causa de pedir), pode o executado propor uma ação autónoma de impugnação da execução (...) com base em outra causa de pedir, que poderia, no entanto, ter sido deduzidas nos primeiros embargos?" 63 .

Este Ilustre Processualista responde de forma negativa, defendendo que o executado não pode fragmentar a sua oposição à execução, pois tal traduzirá uma atitude desleal e

numa só causa, as quais acarretam uma definição de «(...) res iudicata effect more broadly than in earlier times», John B. OAKLeY; VIKRAM D. Amar. American Civil Procedure: A guide to civil adjudication in US Courts, Kluwer Law International, 2009, p. 251

${ }^{58}$ Cf., sublinhando estas ideias, MARINONI, Luiz Guilherme. Coisa julgada sobre questão. Thomson Reuters, 2018, sobretudo p. 51-53; 97.

${ }^{59}$ Cf. MARQUES, João Paulo Remédio. Acção declarativa à luz do Código Revisto. 3. ed. Coimbra: Coimbra Editora, p. 470-471 (itálico do Autor).

60 Vide, rejeitando o ónus de reconvir, de criação jurisprudencial, CAPELO, Maria José, Ónus de reconvir e caso julgado. Revista de Legislação e Jurisprudência, ano 150, n. 4024, set/out. 2020, p. 52-63.

${ }^{61}$ Cf. Lebre de Freitas/Isabel Alexandre. Código de Processo Civil Anotado. 4. ed., Almedina, p. 28. v. 1. (anotação ao artigo $3 .^{\circ}$ ).

${ }^{62}$ Cf. WOLFANG HAU, ob.cit., sobretudo p.47; 57-58.

63 Cf. Didier Jr., Fredie, In: Comentários ao Novo Código de Processo Civil [CABRAL, Antonio do Passo; CRAMER, Ronaldo (coord.)], cit., p. 784. 


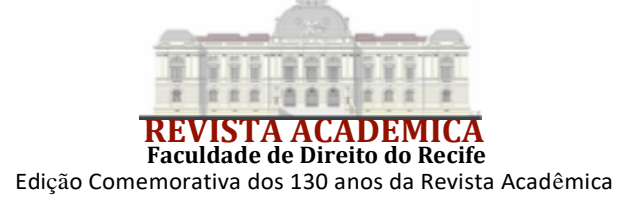

contrária à duração razoável do processo e à boa fé processual ${ }^{64}$. No entanto, a razão para apresentar tal solução assenta num pressuposto de que "os embargos são sunstancialmente defesa do executado", logo o regime da eficácia preclusiva deve ser semelhante ao do réu (na ação de conhecimento) ${ }^{65}$.

Num entendimento oposto, LUIZ Rodrigues WAMBIER E EDUARDO TALAMINI sustentam que os embargos ${ }^{66}$ constituem:

"ação de conhecimento, geradora de processo incidental e autónomo, mediante a qual, com a eventual suspensão da execução, o executado impugna a pretensão creditícia do exequente e a validade do processo executivo ${ }^{67 ",}$, assinalando que a sentença de mérito dos embargos fará caso julgado nos limites do pedido e das causas de pedir que o embargante $\operatorname{apresentar}^{68}$.

À luz do regime processual português os embargos configuram uma "contra-ação" de cariz declarativo, funcionalmente coordenados com o processo executivo (correndo por apenso), desencadeados com o objetivo de extinção (total ou parcial) da execução, seja por motivos processuais ou de mérito. Ambiciona-se, por conseguinte, o fim da execução mediante o reconhecimento da atual inexistência do direito exequendo ou da falta de um pressuposto, específico ou geral, da ação executiva ${ }^{69}$.

A este efeito extintivo, associa-se o efeito de caso julgado da decisão (nos embargos de executado) quando a oposição é de mérito. Naqueles casos em que o executado dirija o seu ataque à obrigação exequenda, quebrando a proteção da literalidade e abstracção inerente a um título executivo, a declaração judicial torna indiscutível a existência, exigibilidade e validade da obrigação exequenda ${ }^{70}$ (cf. n. ${ }^{\circ} 5$ do artigo $732 . .^{\circ}$ ).

De forma clara, Miguel TEIXEIRA DE SOUSA explicita que:

“ (...) o sentido do estabelecido no art. $732 .^{\circ}, \mathrm{n}^{\circ}$, , só pode ser este: a partir do momento em que se verifica o trânsito em julgado da decisão de improcedência da oposição à execução deduzida com um certo fundamento de inexistência, invalidade ou inexigibilidade da obrigação exequenda, a preclusão da invocação de um fundamento distinto daquele que foi alegado pelo executado passa a operar através da excepção de caso julgado"71.

A originalidade do sistema não se esgota na imputação deste valor de caso julgado material à decisão de mérito ${ }^{72}$. Evidencia-se no âmbito objectivo sobre o qual se forma caso julgado: a indiscutibilidade estende-se sobre a(s) causa(s) de pedir que forem deduzidas na

${ }^{64}$ Didier Jr., Fredie, idem.

65 Ibidem.

${ }^{66}$ Note-se que, no sistema brasileiro, os embargos apenas são utilizados no processo de execução do título extrajudicial, sendo que a impugnação ao cumprimento da sentença é o meio de se opor à execução de título judicial.

${ }^{67}$ WAMBIER, Luiz Rodrigues; TALAMINI, Eduardo. Curso avançado de processo civil 18. ed. São Paulo: Thomson Reuteus Brasil, 2021. p. 547-548. v. 3.

68 WAMBIER, Luiz Rodrigues; TALAMINI, Eduardo, ob.cit., idem. Explicita-se que não ficam precludidas as causas de inexistência do direito do exequente, podendo o executado propor uma demanda para discuti-los (embora já não através dos embargos, como incidente da execução).

${ }^{69}$ Cf. Freitas, José Lebre de. A ação executiva à luz do Código de Processo Civil de 2013. 7. ed. Coimbra: Gestlegal, 2017. p. 195.

70 O título executivo "constitui base da presunção da existência e titularidade da obrigação exequenda" [Cf. Freitas, José Lebre de. A ação executiva à luz do Código de Processo Civil de 2013, cit., p.93, nota (89)].

${ }^{71}$ Cf. SOUSA, Miguel Teixeira de. Preclusão e Caso julgado, cit., p. 14.

${ }^{72}$ Cf. artigo 619.․ Repare-se que, nas ações declarativas, a autoridade de caso julgado está sujeita aos limites objetivos e subjetivos definidos no artigo $581 .^{\circ}$ do CPCPt. 
petição de embargos e sobre aquelas que sriam suscetíveis de ser alegadas e não o foram ${ }^{73}$.

Ou seja, a especificidade desta opção legislativa - eventualmente ancorada nas garantias que rodeiam atualmente esta ação declarativa que corre por apenso - reside precisamente no facto de os embargos serem a "última" oportunidade para o executado esgotar todos os meios de ataque ${ }^{74}$.

As consequências, em matéria de ónus de alegação, são evidentes: perante a indiscutibilidade que se forma sobre a obrigação exequenda recairá sobre o executado o ónus de indagação exaustiva e alegação dos factos (extintivos, modificativos e impeditivos) que se possam repercutir na obrigação exequenda [e que não estejam sujeitos à preclusão temporal da alínea g) do artigo $729 .{ }^{\circ}$ do $\mathrm{CPCPt}^{75}$ ].

Em suma, tal como está gizada na lei, a apresentação da petição (dos embargos) acarreta um extenso ónus de alegação. Note-se que não está em causa a aplicabilidade do princípio da concentração de toda a defesa na contestação (artigo 573. ${ }^{\circ}$ do $\mathrm{CPCPt}$ ), mas uma nova directriz no sentido de exigir ao executado (que assume a posição de autor neste enxerto declarativo) uma "concentração" de todos os fundamentos que possam abalar a obrigação exequenda ${ }^{76}$. Impor-se-á assim ao executado um esforço probatório de toda a factualidade que seja suscetível de colocar em causa a existência, exigibilidade e validade da obrigação exequenda.

Sustentar-se-á, em abono do regime do n. $^{\circ} 5$ do artigo $732 .^{\circ}$, que este traduz o resultado de uma ponderação entre os interesses do exequente (favor creditoris) e os interesses do executado, privilegiando-se o primeiro, pois tem a seu favor um direito formal (à satisfação coerciva) assente no título executivo.

73 Perante o regime espanhol, a decisão de mérito da oposição à execução não tem força de caso julgado material (vide, por todos, MONTERO AROCA, Juan et al (org.). Derecho Jurisdiccional II (Proceso Civil). 21. ed. Valencia: Tirant Lo Blanch, 2013, p. 604- 605).

74 No sistema processual alemão, o efeito preclusivo de alegação das "exceções" é intraprocessual, visando evitar novas oposições. Explicando este efeito preclusivo à luz do § 767, III, (relativo a oposição fundada em título não judicial), MUSIELAK; VOIT; LACKMANN. Zivilprozessordnung. 15. ed., Vahlen, 2018., § 767, anotação n. 42; e, a propósito, da não formação de caso julgado material sobre as exceções, ressalvando a aplicação analógica do $\S 322,2$, do ZPO (relativo à compensação), anotação n. ${ }^{\circ}$ 46. Perante o regime da oposição de mérito, HANS BROX E WOLFDIETRICH WALKER sufragam a tese dominante no sentido de a oposição visar a eliminação da força executiva (e por isso a caracterizam como uma ação constitutiva processual) mas admitem a possibilidade de ser formulado, ao abrigo do $\S 256$ II ZPO, pela parte interessada, um pedido declaratório incidental destinada à apreciação da "questão prejudicial" (isto é, a inexistência ou inexistência da pretensão titulada) com força de caso julgado material -(Cf., ressalvando o regime especial da compensação, por aplicação do § 322 II ZPO, Zwangsvollstreckungsrecht, 11. ed., München: Vahlen, 2018, expressamente p. 612; 613; 644-646).

75 Fundando-se a execução em sentença, a oposição pode ter como fundamento qualquer facto extintivo ou modificativo da obrigação, desde que seja posterior ao encerramento da discussão no processo de declaração e se prove por documento (salvo a hipótese da prescrição do direito ou da obrigação que pode ser provada por qualquer meio).

76 Com implicações em matéria de aplicabilidade do regime atinente aos vícios da petição inicial (previsto no artigo 186. ${ }^{\circ}$ do CPCPt), nomeadamente na "dispensa" de compatibilidade substancial entre as "causas de pedir". Como se afirma no Acórdão da Relação de Coimbra, de 3/03/2020, Processo n. ${ }^{\circ}$ 289/19.18SRE-A.C1, in www.dgsi.pt. “(...) o regime da cumulação de causas de pedir incompatíveis geradora da ineptidão opera no âmbito da acção declarativa (...), mas não parece que deva adaptar-se à petição dos embargos de executado", explicando que "os fundamentos da oposição são todos os que possam ser invocados na defesa ( sistema não restritivo ), não funcionando para essa defesa o regime da incompatibilidade de causas de pedir, além do mais, porque o embargante opõe factos impeditivos, modificativos ou extintivos da obrigação exequenda (oposição de mérito), funcionando o princípio da concentração". 


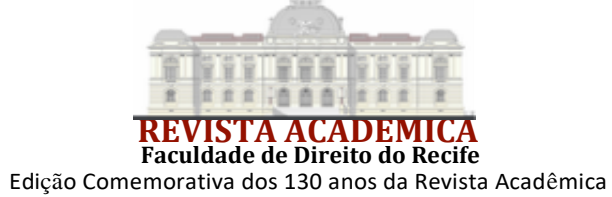

No entanto, a força de caso julgado recairá em “objecto virtual” (que poderá ou não corresponder ao objecto efectivamente apreciado e julgado). Tais limites "virtuais" do caso julgado - sobre a existência, validade e exigibilidade da obrigação exequenda - precludem, para o futuro, qualquer reação posterior do executado. Como explica RUI PINTO:

"Tampouco poderá o devedor vencido, consoante as situações concretas, colocar uma ação autónoma de simples apreciação negativa da dívida ou pedir a restituição do indevido se já tiver pago uma obrigação extinta" 77 .

\section{CONSIDERAÇÕES FINAIS}

No direito processual português, a dimensão do ónus de alegação varia em função da posição que o sujeito tem na lide. Em nome do princípio do dispositivo, priviligia-se a liberdade de o autor conformar o objeto da causa quando submete a petição a juízo.

Já, porém, é controverso se deve ser exigido, ao sujeito que assume a posição de autor, um ónus de alegação de factos constitutivos supervenientes, nomeadamente quando consubstanciem uma nova causa de pedir (emergente da mesma relação jurídica controvertida) para efeitos de exaurir a litigiosidade inerente a uma situação substantiva.

Para além de razões fundadas em economia processual e da exigibilidade de uma litigância ancorada na boa fé, a necessidade de pacificação total do litígio pode justificar um esgotamento de todos os fundamentos que suportem uma determinada pretensão. O esforço processual que será exigido ao autor não será excessivo se este ónus de alegar factos supervenientes se circunscrever à factualidade juridicamente relevante que "surja" nos autos (nomeadamente por via da atividade probatória).

Quanto ao réu, o ónus de alegação é um verdadeiro ónus de concentração de toda a defesa na ação relativamente à pretensão que contra ele foi deduzida. Os factos impeditivos, extintivos e modificativos do direito do autor perdem a sua relevância uma vez transitada em julgado a decisão que ponha termo à causa (o denominado efeito preclusivo do caso julgado). Se , mais tarde, se quiser fazer valer de um facto não alegado na ação pretérita, como fundamento de uma nova ação (na posição de demandante), o tribunal deve considerar que a exceção de caso julgado obsta ao seu conhecimento, sob pena de se gerar situação contrária à já definida judicialmente.

Todavia, em matéria de ónus imputado à parte passiva, somos de opinião de que não é defensável um ónus de reconvir, salvo em casos excecionais tipificados na lei. Ou seja, competirá ao réu decidir da oportunidade processual do exercício de uma pretensão própria, em nome da igualdade de acesso à justiça e do princípio da disponibilidade da tutela jurisdicional, mesmo que se verifique uma identidade/conexão com a factualidade que suporta a pretensão do autor.

Nos embargos de executado, é controversa a bondade da solução legal no sentido de se ter optado por exigir a concentração de todos os meios de defesa atinentes à existência, exigibilidade e validade da obrigação (n. ${ }^{\circ} 5$ do artigo $732 .^{\circ}$ do CPCPt). Tal significará que, uma vez dirimida a oposição à execução, lidaremos eventualmente com um caso julgado sobre um objeto não real, ou seja sobre questões não efetivamente julgadas. Por isso, a aparente justeza e a proporcionalidade da solução legal - perante a força probatória especial do título e a aparência da existência da obrigação exequenda - nem sempre serão evidentes.

Em suma, em busca de um processo equitativo, é importante continuar a refletir, como adverte ANTONIO CARRATTA, não tanto sobre a justificação dos mecanismos preclusivos no plano da teoria geral do processo, mas sobretudo em torno da sua"dosagem" (dosaggio)

77 Cf. PINTO, Rui. A ação executiva. Lisboa: Editora AAFDL, 2018. p. 437-438. 
consagrada na lei $^{78}$.

\section{REFERÊNCIAS}

A AÇÃO executiva à luz do Código de Processo Civil de 2013. 7. ed. Coimbra: Gestlegal, 2017.

A AÇÃO executiva. Lisboa: Editora AAFDL, 2018.

A SENTENÇA entre a Autoridade e a Prova: em busca dos traços distintivos do caso julgado civil. Coimbra: Almedina, 2016.

AS PARTES, o objecto e a prova na acção declarativa. Lisboa: Lex, 1995.

ALBUQUERQUE, Pedro de. Responsabilidade processual por litigância de má-fé, abuso de direito e responsabilidade civil em virtude de actos praticados no processo. Coimbra: Almedina, 2006

ALmeIDA, Francisco Manuel Lucas Ferreira de. Direito Processual Civil. 2. ed. Coimbra: Almedina, 2019. v. 2.

Andrade, Manuel A. Domingues de. Noções Elementares de Processo Civil. Coimbra: Coimbra Editora, 1979.

AzEvedo, Gustavo. Ônus e deveres processuais. Revista Acadêmica da Faculdade de Direito do Recife, v. 92, n. 2, p. 232-250, dez. 2020.

BROX, Hans et al. (org.). Zwangsvollstreckungsrecht. 11. ed. München: Vahlen, 2018.

CABral, Antonio do Passo. Coisa julgada e preclusões dinâmicas: entre continuidade, mudança e transição de posições processuais estáveis. 3. ed. Salvador: Editora JusPODIVM, 2018.

CABRAL, Antonio do Passo; CRAMER, Ronaldo (coord.). Comentários ao novo

Código de Processo Civil. Rio de Janeiro: Forense, 2015.

CALAZA LóPEZ, Sonia. La cosa juzgada. Madrid: La Ley, 2009.

CAPELO, Maria José. Os factos notórios e a prova dos danos não patrimoniais. Revista de Legislação e Jurisprudência, Coimbra, ano 143, p. 286-304, mar./abr.2014.

CARRATTA, Antonio. II fondamento del principio di preclusione nel processo civile. Il principio di preclusione nel processo penale. Torino: G.Giappichelli Editora, 2012.

ChIOvenda, Giuseppe. Cosa giudicata e preclusione. Rivista Italiana per le Scienze

Giuridiche, Torino, n. 11, p. 3-53, 1933.

CÓDIGO de Processo civil Anotado. 4. ed. Coimbra: Almedina. [2---?]. v. 1.

${ }^{78} \mathrm{Cf}$. CARRATTA, Antonio. II fondamento del principio di preclusione nel processo civile, cit., p. 22. 


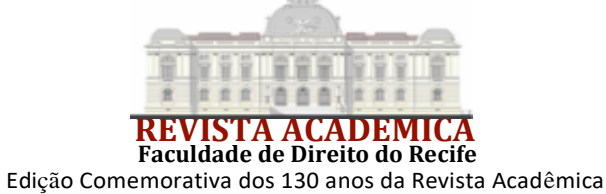

CORDEIRO, António Menezes. Litigância de Má-fé, Abuso do direito de acção e culpa "in agendo". 3. ed. Coimbra: Almedina, 2016.

CunHA, Leonardo Carneiro da. A atendibilidade dos fatos supervenientes no processo civil: uma análise comparativa entre o sistema português e o brasileiro. Coimbra: Almedina, 2012.

De la Oliva Santos, Andrés. Objeto del Processo y Cosa juzgada en el proceso civil.

Navarra: Thomson-Civitas, 2005.

De la Oliva Santos, Andrés; Diez -Picazo Giménez, Ignacio. Derecho Procesal Civil: el Processo de declaración. 3. Ed. Editoral Universitaria Ramón Areces, 2004.

DIDIER JR, Fredie. Curso de Direito Processual Civil. 17. ed. Salvador: Editora JusPODIVM, 2015. v. 1 .

ESTUDOS sobre o Novo Processo Civil. 2. ed. Lisboa: Lex, 1997.

FREITAS, José Lebre de. Um polvo chamado autoridade do caso julgado. Revista da Ordem dos Advogados, Lisboa, ano 79, n. 3-4, p. 691-722, jul./dez. 2019.

Freitas, José Lebre de et al. (org.). Código de Processo Civil Anotado. 3. ed. Coimbra: Almedina, 2018. v. 2.

Geraldes, António Santos Abrantes et al (org.). Código de Processo Civil Anotado I: Parte Geral e Processo de Declaração. 2. ed. Coimbra: Almedina, 2021.

HAU, Wolfang. "Widerklageprivileg und Widerklagelast" Zeitschrift für Zibilprozess, Berlim, n. 1, 2004.

Mandrioli, Crisanto. Corso di Diritto Processuale Civile. 12. ed. Torino: Giappichelli, 1998. v. 3 .

MARINONI, Luiz Guilherme. Coisa julgada sobre questão. São Paulo: Thomson Reuters 2018.

MARQues, João Paulo Remédio. Acção declarativa à luz do Código Revisto. 3. ed. Coimbra: Coimbra Editora, 2011.

MENCHINI, Sergio. II giudicato civile. 2. ed. Torino: Utet, 2002.

Mendes, João de Castro. Limites objetivos do Caso Julgado em Processo Civil. Lisboa:

Edições Ática, 1968.

Mesquita, Miguel. Reconvenção e Excepção no Processo Civil. Coimbra: Almedina, 2009.

Montero Aroca, Juan et al (org.). Derecho Jurisdiccional II (Proceso Civil). 21. ed. Valencia: Tirant Lo Blanch, 2013.

MUSIELAK, Hans-Joachim et al (org.). Zivilprozessordnung. 17. ed. München: Vahlen, 2020.

NIEHOFF, Gerrit Cornelius. Verfahrenskonzentration durch compulsory counterclaim in den 
US-amerikanischen Zivilprozessordnung. Tübingen: Mohr Siebeck, 2014.

NULIDADES no Processo Moderno: Contraditório, Protecção da Confiança e Validade Prima Facie dos Atos Processuais. 2. ed. Rio de Janeiro: Editora Forense, 2010.

OAKLey, John B. et al (org.). American Civil Procedure: A guide to civil adjudication in US Courts. Kluwer Law International, 2009.

PINTO, Rui. Exceção e autoridade de caso julgado: algumas notas provisórias. Julgar online, nov. 2018. Disponível em: http://julgar.pt/excecao-e-autoridade-de-caso-julgado-algumas-notasprovisorias/. Acesso em: 01 set. 2021.

PRECLUSÃO e contrário contraditório. Cadernos de Direito Privado, Braga, n. 41, p. 28, 2013.

PRECLUSÃO e Caso Julgado. Disponível em: academia.edu/22453901/TEIXEIRA_DE_SOUSA_M._Preclusão_e_caso_julgad_02.2016. Acesso em: 01 set. 2021.

RAUSCHER, Thomas et al. (org.). Münchener Kommentar zur Zivilprozessordnung mit Gerichtsverfassungsgesetz und Nebengesetzen. 6. ed. München: Verlag C.H. Beck, 2020.

ReIs, José Alberto dos. Código de Processo Civil Anotado. Coimbra: Coimbra Editora, 1984. v. 5.

Rodrigues, Marco António dos Santos. A modificação do pedido e da causa de pedir no processo civil. Rio de Janeiro: Mundo Jurídico, 2014.

SousA, Miguel Teixeira de. Algumas questões sobre o ónus de alegação e de impugnação em processo civil. Scientia Iuridica, Braga, n. 332, 2012, p. 395-412. t. 62.

TAPIA FERnÁnDEZ, Isabel. El objeto del processo. Alegaciones. Sentencia. Cosa Juzgada. Madrid: Editorial La Ley, 2000.

VARElA, João Antunes et al (org.). Manual de Processo Civil. 2. ed. Coimbra: Coimbra Editora, 1985.

VOLPINO, Diego. L'oggetto del giudicato nell'esperienza americana. Padova: Cedam, 2007.

WAMBIER, Luiz Rodrigues et al (org.). Curso avançado de processo civil. 18. ed. São Paulo: Thomson Reuteurs Brasil, 2021. v. 3. 